\title{
POTENCIAL DA PALHA DE CANA-DE-AÇÚCAR PARA PRODUÇÃO DE ETANOL
}

\author{
Fernando A. Santos*, José H. de Queiróz, Jorge L. Colodette, Sergio A. Fernandes, Valéria M. Guimarães e Sebastião T. \\ Rezende \\ Universidade Federal de Viçosa, Av. Peter Henry Rolfs, s/n, 36570-000 Viçosa - MG, Brasil
}

Recebido em 26/4/11; aceito em 11/11/11; publicado na web em 13/1/12

\begin{abstract}
POTENTIAL OF SUGARCANE STRAW FOR ETHANOL PRODUCTION. Sugarcane straw biomass accounts for $1 / 3$ of the energy potential of sugarcane and represents a rich source of sugars. Studies have been intensified for the use of this biomass along with bagasse for the production of cellulosic ethanol. Development of this technological path will allow for taking full advantage of sugarcane, increasing ethanol production without expanding the area cultivated. However, in order for this technology to be viable certain challenges must be overcome, including establishment of appropriate conditions of pretreatment and hydrolysis of these materials for release of fermentable sugars.
\end{abstract}

Keywords: sugarcane straw; lignocelullosic biomass; ethanol.

\section{INTRODUÇÃO}

A iminente escassez das reservas de petróleo, principal fonte energética mundial, juntamente com as preocupações da sociedade com a preservação ambiental, são os principais motivos que levaram os governos a buscarem estratégias para uma maior produção e maior consumo de combustíveis que sejam renováveis e sustentáveis. ${ }^{1,2}$

Um dos principais objetivos do uso dos biocombustíveis é a substituição de combustíveis fósseis, permitindo a diminuição da dependência por recursos não renováveis e a redução das emissões de gases de efeito estufa. A queima de combustíveis fósseis representa aproximadamente $82 \%$ das emissões dos gases causadores do efeito estufa. ${ }^{3}$ Portanto, seja pela questão ambiental global, seja pela importância em reduzir a dependência externa de energia, o etanol de cana-de-açúcar, que já apresenta indicadores ambientais muito positivos quando comparado a outras opções, representa uma alternativa viável na substituição de combustíveis fósseis. ${ }^{4}$

O etanol obtido do caldo de cana-de-açúcar (etanol de primeira geração) é, até o momento, o único combustível com capacidade de atender à crescente demanda mundial por energia renovável de baixo custo e de baixo poder poluente. Deve-se considerar que as emissões gasosas com a queima do etanol são da ordem de $60 \%$ menores se comparadas às emissões da queima da gasolina, sendo ainda que o do $\mathrm{CO}_{2}$ emitido é reabsorvido pela própria cana. ${ }^{5}$

Atualmente, o etanol é produzido praticamente a partir de matérias-primas sacarinas ou amiláceas, cana-de-açúcar e milho, respectivamente. Entretanto, há um grande esforço da comunidade científica para o desenvolvimento de novos processos economicamente viáveis para o aproveitamento da componente lignocelulósica da biomassa, caso dos resíduos agrícolas (palha e bagaço de cana-de-açúcar, palha de trigo e resíduos de milho) e resíduos florestais (pó e restos de madeira), assim como o capim elefante para produção de etanol combustível (etanol de segunda geração). ${ }^{6,7}$

O mais abundante recurso biológico renovável da terra é a biomassa lignocelulósica. ${ }^{8}$ Estima-se que somente os EUA têm potencial para produzir mais de 1,3 bilhões de toneladas (base seca) de biomassa por ano. ${ }^{9}$ Segundo Zhang, ${ }^{10}$ um bilhão de toneladas de biomassa seca produz entre 80-130 bilhões de galões de etanol celulósico. Contudo, para obter sistemas que sejam economicamente viáveis e

\footnotetext{
*e-mail: falmeidasantos81@yahoo.com.br
}

sustentáveis é necessário utilizar eficientemente todas as frações das matérias-primas, especialmente, a celulose, hemicelulose e lignina. ${ }^{11}$ De acordo com Das et al., ${ }^{12}$ o consumo de celulose é três vezes maior do que o consumo do aço e equivale ao consumo de cereais.

Entre os diferentes tipos de biomassas lignocelulósica, a palha de cana-de-açúcar se destaca como fonte energética (Esquema 1). A palha apresenta grande potencial para geração de calor, eletricidade e produção de etanol celulósico. O aproveitamento da palha deverá ocupar um lugar de destaque como matéria-prima para a produção de etanol combustível. De acordo com Ripoli, ${ }^{13}$ uma tonelada de palha equivale a algo entre 1,2 a 2,8 EBP (equivalentes barris de petróleo). Consequentemente, a não utilização dessa biomassa desperdício energético.

A tecnologia de conversão de biomassa lignocelulósica em açúcares fermentáveis para a produção de etanol vem sendo considerada como uma alternativa promissora para atender à demanda mundial por combustíveis. Apesar de já existirem tecnologias disponíveis para o processamento da celulose, a maioria esbarra em dificuldades técnicas ou econômicas. ${ }^{6,14,15}$

Nesse sentido, um dos principais gargalos que envolvem a produção de etanol celulósico é "desmontar" a parede celular liberando os polissacarídeos como fonte de açúcares fermentescíveis de forma eficiente e economicamente viável. Os açúcares presentes na palha de cana-de-açúcar encontram-se na forma de polímeros (celulose e hemicelulose) e são recobertos por uma macromolécula (lignina), formando a microfibrila celulósica. Devido à sua interação intermolecular e completa ausência de água na estrutura da microfibrila, a celulose apresenta estrutura bastante recalcitrante difícil de ser desestruturada e convertida em monossacarídeos fermentescíveis. ${ }^{16}$

Por esse motivo, o rendimento líquido da conversão da celulose em glicose livre e, a seguir, em etanol é desfavorável, com as tecnologias disponíveis. Tornar os rendimentos favoráveis possibilitará o melhor aproveitamento dessa rica matéria-prima natural encontrada na palha de cana-de-açúcar, atualmente desperdiçada ou utilizada de forma menos nobre ${ }^{17}$ Neste contexto, o objetivo deste trabalho foi fazer uma revisão sobre a estrutura recalcitrante da palha de cana-de-açúcar e o seu potencial uso na produção de etanol celulósico.

\section{CARACTERÍSTICAS ESTRUTURAIS DA BIOMASSA LIGNOCELULÓSICA}

A biomassa lignocelulósica constitui a maior fonte de carboidratos 


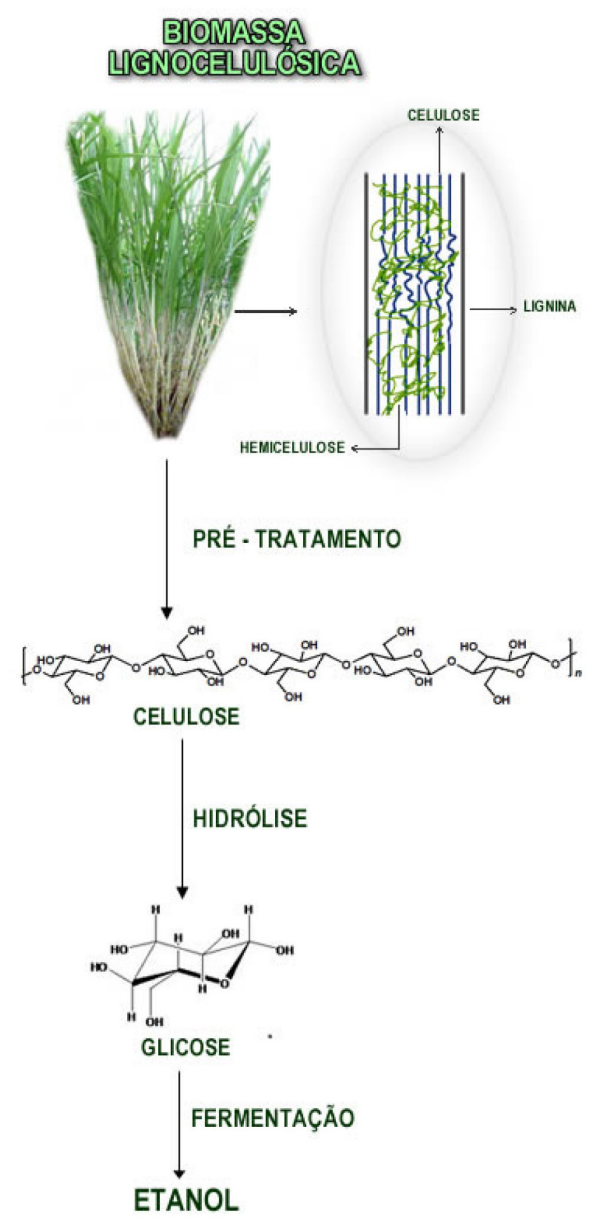

Esquema 1. Representação esquemática da produção de etanol a partir de biomassa lignocelulósica

naturais do mundo. A dificuldade de converter a biomassa lignocelulósica em insumos químicos é atribuída às suas características químicas e morfológicas. Esses materiais lignocelulósicos são constituídos de fibras de celulose envolvidas em uma matriz amorfa de polioses e lignina. Essa matriz amorfa age como uma barreira natural ao ataque de micro-organismos e/ou enzimas e torna esses materiais estruturalmente rígidos e pouco reativos. ${ }^{16} \mathrm{~A}$ composição química da biomassa lignocelulósica, geralmente contém $35-50 \%$ de celulose, seguido de $20-35 \%$ de hemicelulose, $10-25 \%$ de lignina e uma pequena quantidade de cinzas e extrativos. Esta composição química varia em função do tipo de biomassa, conforme mostrado na Tabela 1 .

A celulose é o polímero natural de maior ocorrência no mundo (Figura 1). A sua estrutura pode ser classificada em três níveis organizacionais. O primeiro é definido pela sequência de resíduos $\beta$-D-glicopiranosídicos unidos por ligações covalentes, formando o homopolímero de anidroglicose com ligações $\beta$-D $(1 \rightarrow 4)$ glicosídicas, de fórmula geral $\left(\mathrm{C}_{6} \mathrm{H}_{10} \mathrm{O}_{5}\right)_{\mathrm{n}}$. O segundo nível descreve a conformação molecular, isto é, a organização espacial das unidades repetitivas, e é caracterizado pelas distâncias das ligações e respectivos ângulos e pelas ligações de hidrogênio intramoleculares. O terceiro nível define a associação das moléculas formando agregados com uma determinada estrutura cristalina. Estes agregados conferem elevada resistência à tensão, tornando a celulose insolúvel em água e em um grande número de outros solventes. ${ }^{18,19}$

As hemiceluloses são heteropolissacarídeos complexos compostos por $D$-glucose, $D$-galactose, $D$-manose, $D$-xilose, $L$-arabinose, ácido $D$-glucurônico e ácido 4- $O$-metil-glucurônico (Figura 2). São estruturalmente mais semelhantes à celulose do que a lignina. Sua
Tabela 1. Composição química de biomassas lignocelulósicas com potencial para produção de etanol de segunda geração ${ }^{23,63}$

\begin{tabular}{|c|c|c|c|}
\hline Biomassa Lignocelósica & $\%$ Celulose & $\%$ Hemicelulose & $\%$ Lignina \\
\hline Palha de cana & $40-44$ & $30-32$ & $22-25$ \\
\hline Bagaço de cana & $32-48$ & $19-24$ & $23-32$ \\
\hline Madeira dura & $43-47$ & $25-35$ & $16-24$ \\
\hline Madeira mole & $40-44$ & $25-29$ & $25-31$ \\
\hline Talo de milho & 35 & 25 & 35 \\
\hline Espiga de milho & 45 & 35 & 15 \\
\hline Algodão & 95 & 2 & 0,3 \\
\hline Palha de trigo & 30 & 50 & 15 \\
\hline Sisal & 73,1 & 14,2 & 11 \\
\hline Palha de arroz & 43,3 & 26,4 & 16,3 \\
\hline Forragem de milho & $38-40$ & 28 & $7-21$ \\
\hline Fibra de coco & $36-43$ & $0,15-0,25$ & $41-45$ \\
\hline Fibra de bananeira & $60-65$ & $6-8$ & $5-10$ \\
\hline Palha de cevada & $31-45$ & $27-38$ & $14-19$ \\
\hline
\end{tabular}

Figura 1. Representação esquemática da molécula de celulose

estrutura apresenta ramificações que interagem facilmente com a celulose, dando estabilidade e flexibilidade ao agregado. ${ }^{20}$ Comparadas com a celulose, as hemiceluloses apresentam maior susceptibilidade à hidrólise ácida, pois oferecem uma maior acessibilidade aos ácidos minerais comumente utilizados como catalisadores. Esta reatividade é usualmente atribuída ao caráter amorfo destes polissacarídeos. ${ }^{16}$

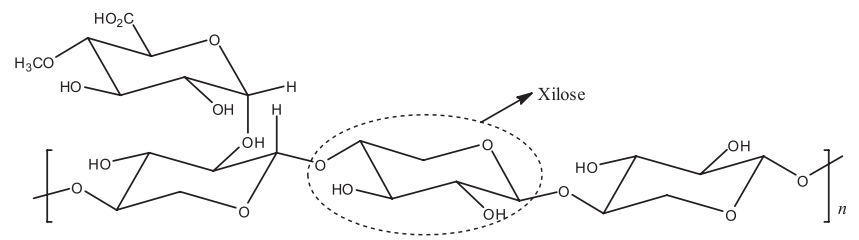

Figura 2. Representação esquemática da hemicelulose

A lignina, depois da celulose, é a macromolécula mais abundante dentre as biomassas lignocelulósicas (Figura 3). É um heteropolímero amorfo que consiste em três diferentes unidades de fenilpropanos: álcool $p$-cumarílico, álcool coferílico e álcool sinapílico. ${ }^{16} \mathrm{~A}$ estrutura da lignina não é homogênea, possui regiões amorfas e estruturas globulares. A composição e a organização dos constituintes da lignina variam de uma espécie para outra, dependendo da matriz de celulose-hemicelulose. No processo de hidrólise enzimática dos materiais lignocelulósicos, a lignina atua como uma barreira física para as enzimas que podem ser irreversivelmente capturadas pela lignina e, consequentemente, influenciar na quantidade de enzima requerida para a hidrólise, assim como dificultar a recuperação da enzima após a hidrólise. ${ }^{21}$

Devido à íntima associação recalcitrante existente entre os três componentes poliméricos da biomassa, a liberação dos polissacarídeos como fonte de açúcares fermentescíveis para produção de etanol está entre as mais importantes e urgentes prioridades nas áreas de pesquisa e desenvolvimento do etanol celulósico. ${ }^{10}$ 


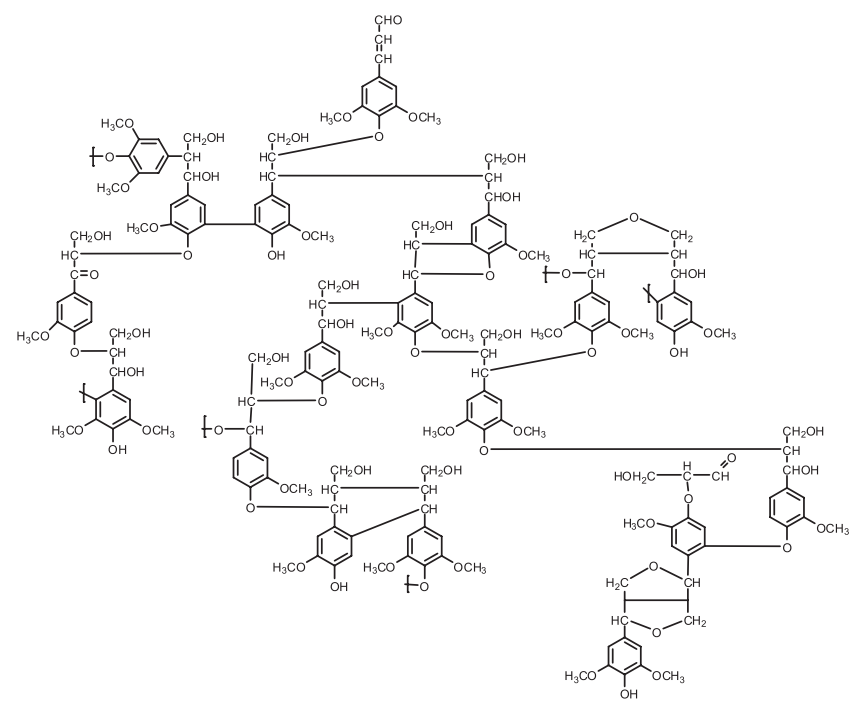

Figura 3. Representação esquemática da lignina de eucalipto

\section{POTENCIAL DA PALHA DE CANA-DE-AÇÚCAR PARA PRODUÇÃO DE ETANOL}

O crescente desenvolvimento alcançado pela agroindústria canavieira, principalmente na produção de etanol combustível, tem gerado um atraente incentivo no aproveitamento do bagaço produzido, devido à inserção de novas e mais avançadas tecnologias agrícolas e industriais, e na recuperação integral ou parcial da palha de cana-de-açúcar. ${ }^{13,22}$

Esse aproveitamento integral da cana permitirá coletar toda a cana-de-açúcar (otimização do processo de colheita), além de otimizar o balanço energético da usina, de forma a aumentar a quantidade de biomassa disponível para ser convertida em etanol..$^{22,23}$

Os processos convencionais de colheita manual, com queima prévia ou mecânica, visam exclusivamente ao aproveitamento do colmo da cana. Em ambos os casos, o aproveitamento da palha não faz parte do processo de colheita. ${ }^{24}$ No entanto, cônscio dos danos ao meio ambiente causados pelas queimadas dos canaviais, essa realidade vem se modificando, seja com a intervenção de órgãos públicos ou por meio de representantes do setor sucroenergético. ${ }^{22}$ Com o Decreto Federal n. 2.661/98 que estabelece o fim gradativo da queima da cana-de-açúcar para os próximos 20 anos, haverá aumento na disponibilidade de palha para ser recuperada e posteriormente utilizada como nova fonte de biomassa para produção de etanol celulósico. ${ }^{23,24}$

A produtividade média de cana-de-açúcar no Brasil é de 85 toneladas por hectare, sendo que para cada tonelada de cana processada são gerados cerca de $140 \mathrm{~kg}$ de palha e $140 \mathrm{~kg}$ de bagaço em base seca, ou seja, 12 toneladas de palha e 12 toneladas de bagaço. ${ }^{25}$ Considerando que toda glicose vai ser convertida em etanol, o aproveitamento integral da cana-de-açúcar (colmo, palha e bagaço) poderá aumentar significativamente a produção de etanol por hectare, passando dos atuais 7.000 L para aproximadamente $14.000 \mathrm{~L}$, sem necessidade de expansão da área cultivada ${ }^{26-28}$ (Esquema 2). A palha de cana-de-açúcar representa $15 \%$ do peso dos colmos da cana madura, ou $12 \%$ quando seca. ${ }^{13,29} \mathrm{Em}$ termos energéticos a palha representa 1/3 da energia potencial da cana-de-açúcar que, atualmente, é subaproveitada. $22,25,27$

O tecido vegetal da palha de cana apresenta os mesmos componentes químicos que o bagaço ou a madeira. Entretanto, as propriedades físico-mecânicas, geométricas, térmicas e energéticas são diferentes. ${ }^{30}$

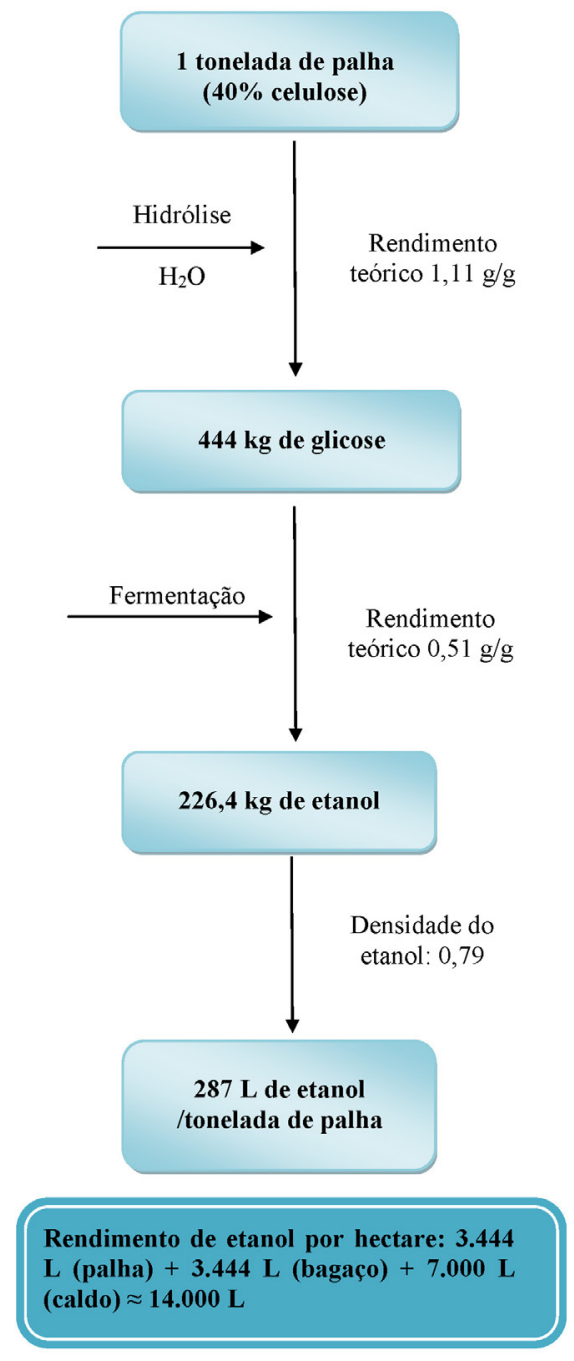

Esquema 2. Rendimento teórico da produção de etanol por hectare

A palha da cana-de-açúcar, sendo toda a parte aérea da planta menos os colmos industrializáveis, é constituída basicamente de celulose, hemicelulose e lignina, na proporção aproximada de 40, 30 e $25 \%$, respectivamente. Trabalhos realizados por Silva ${ }^{31}$ com a palha de cana in natura mostraram que o material apresenta $38 \%$ de celulose, $29 \%$ de hemicelulose e $24 \%$ de lignina. Aguilar et al. ${ }^{32}$ verificaram que a palha de cana apresenta um teor de cinzas entre duas e quatro vezes maior do que o bagaço de cana, variando em função do local de coleta do material, condições climáticas, estádio de desenvolvimento vegetativo e cultivar. ${ }^{23,33}$

A compreensão da complexidade estrutural desses materiais lignocelulósicos requer o conhecimento das propriedades físico-químicas de cada um dos seus componentes para se ter a noção exata do seu potencial energético.

\section{RECALCITRÂNCIA DA BIOMASSA LIGNOCELULÓSICA DA CANA-DE-AÇÚCAR}

Assim como em toda célula vegetal, a parede celular da palha de cana-de-açúcar é composta principalmente por celulose, hemicelulose e lignina (Esquema 3). A reatividade da celulose é determinada tanto pelos grupos funcionais presentes em sua estrutura, como pelas interações físico-química existentes entre as macromoléculas. ${ }^{34}$

As ligações de hidrogênio intramoleculares entre as hidroxilas conferem resistência à celulose. Já as interações intermoleculares entre 


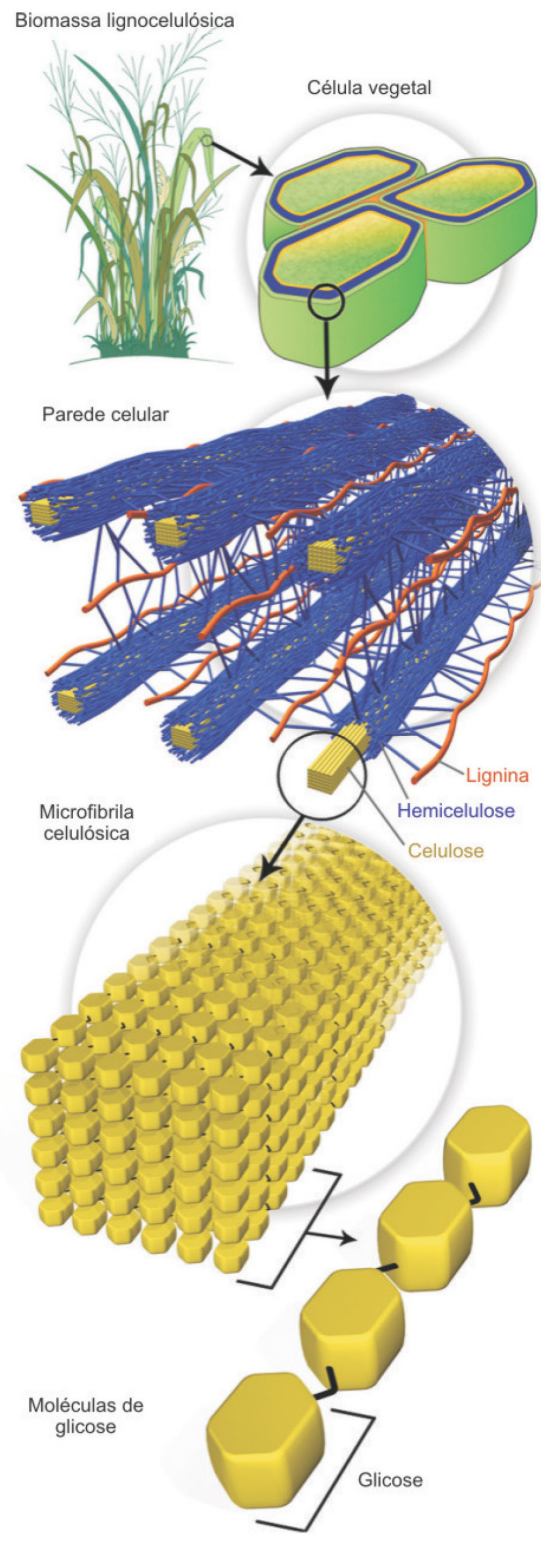

Esquema 3. Estrutura recalcitrante da biomassa lignocelulósica. Adaptado da ref. 37

hidroxilas são responsáveis pela formação da fibra vegetal, ${ }^{35}$ onde de seis a oito moléculas de celulose se alinham paralelamente para formar uma fibra, eliminando as moléculas de água, tornando a microfibrila extremamente longa e resistente (Figura 4). Sobre a superfície das microfibrilas, aderem-se as hemiceluloses que cobrem a celulose, formando o chamado domínio celulose-hemicelulose da parede celular. ${ }^{17}$

As ligações de hidrogênio inter e intramoleculares são responsáveis pela manutenção das regiões cristalinas e tornam a celulose altamente resistente à hidrólise ácida, alcalina ou enzimática. ${ }^{10,36} \mathrm{~A}$ formação de ligações de hidrogênio é o principal fator que influencia as propriedades físicas da celulose, tais como solubilidade, reatividade e cristalinidade. ${ }^{37} \mathrm{~A}$ interação entre os grupos hidroxila via ligações de hidrogênio entre as cadeias limita o acesso de agentes aos grupos funcionais da cadeia, o que dificulta tanto sua solubilização como reações. ${ }^{38}$

A presença de hemicelulose e lignina envolvendo as cadeias de celulose também dificulta o acesso de reagentes e catalisadores, sendo necessário um tratamento prévio para a remoção destes componentes, facilitando o acesso das enzimas à celulose..$^{17}$

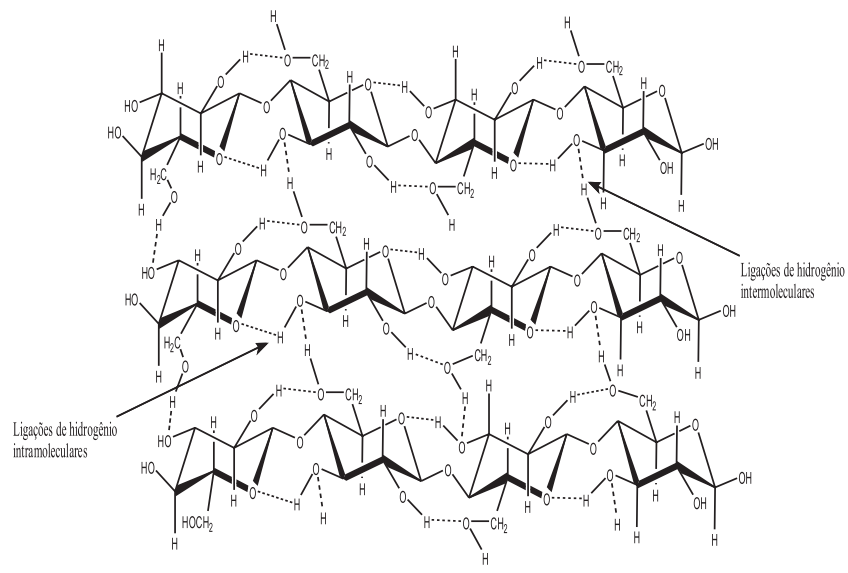

Figura 4. Representação das ligações de hidrogênio supramolecular da celulose

Muitos esforços estão sendo dirigidos para a utilização da celulose de fonte lignocelulósica e de rápido crescimento, como a palha de cana-de-açúcar, para produção de etanol celulósico. A produção de energia baseada na matriz lignocelulósica é uma importante rota alternativa que vem sendo mundialmente estudada. ${ }^{18,39} \mathrm{O}$ interesse pela otimização na obtenção do etanol de celulose vem crescendo muito, conforme já mencionado, em consequência de a celulose corresponder à substância de maior concentração na biomassa e por apresentar uma alta eficiência para produção de etanol quando submetido a reações de hidrólise. ${ }^{16}$

A complexa estrutura da parede celular da biomassa lignocelulósica, no geral, é resistente à bioconversão. A utilização da biomassa como fonte de carboidratos para obtenção de combustíveis e produtos químicos de alto valor agregado tem sido severamente dificultada pela sua recalcitrância. ${ }^{40}$

Diversos autores têm atribuído a recalcitrância da biomassa, principalmente, à cristalinidade, ao grau de polimerização e à baixa acessibilidade das enzimas celulolíticas ao substrato. ${ }^{41-44}$

Devido a essa dificuldade na estrutura da biomassa, muitos processos de produção têm sido desenvolvidos no intuito de converter os carboidratos presentes na biomassa em açúcares fermentescíveis, buscando por melhores rendimentos e menores custos de processamento. ${ }^{2,4,45}$ A produção de etanol a partir de celulose exige várias etapas que envolvem basicamente pré-tratamento, hidrólise e fermentação. ${ }^{6}$ Efetivamente, devido à natureza recalcitrante da biomassa, a etapa de pré-tratamento consiste em uma das etapas operacionais mais relevantes em termos de custo direto, além de influenciar diretamente os custos das etapas anteriores e subsequentes do processo. ${ }^{28,46,47} \mathrm{O}$ pré-tratamento tem por finalidade alterar ou remover a lignina e a hemicelulose, aumentar a área superficial e diminuir o grau de polimerização e cristalinidade da celulose, o que acarreta em aumento na digestibilidade do complexo enzimático e, consequentemente, em elevados rendimentos em açúcar., ${ }^{4,84}$

A relação entre a caracteristica da estrutura da celulose e as taxas de hidrólise enzimática tem sido extensivamente estudada, mas ainda não existe tecnologia hidrolítica que seja economicamente viável e sustentável..$^{40}$ Tais características, como cristalinidade da celulose, área superficial específica, grau de polimerização, proteção da celulose pela lignina e hemicelulose, são consideradas fatores que interferem na eficiência de hidrólise. ${ }^{49,50}$ A relação entre fatores estruturais reflete a complexidade da recalcitrância da biomassa lignocelulósica. A variabilidade dessas características explica o grau de digestibilidade enzimática entre diferentes fontes de biomassa. ${ }^{6}$

Sendo assim, a utilização dos diferentes componentes passíveis de serem obtidos a partir de biomassa lignocelulósica requer a separação 
seletiva dos mesmos. Isto implica na ruptura do complexo celulose-hemicelulose-lignina e na remoção de cada fração por técnicas de pré-tratamento para degradação enzimática (Esquema 4). Vários métodos de pré-tratamentos têm sido propostos e desenvolvidos. Esses métodos podem ser classificados de diferentes formas, pré-tratamentos físicos, químicos, biológicos ou uma combinação destes no intuito de reduzir a recalcitrância da biomassa lignocelulósica. Dentre estes métodos, os pré-tratamentos químicos e combinados têm recebido uma maior atenção, já que removem a lignina sem

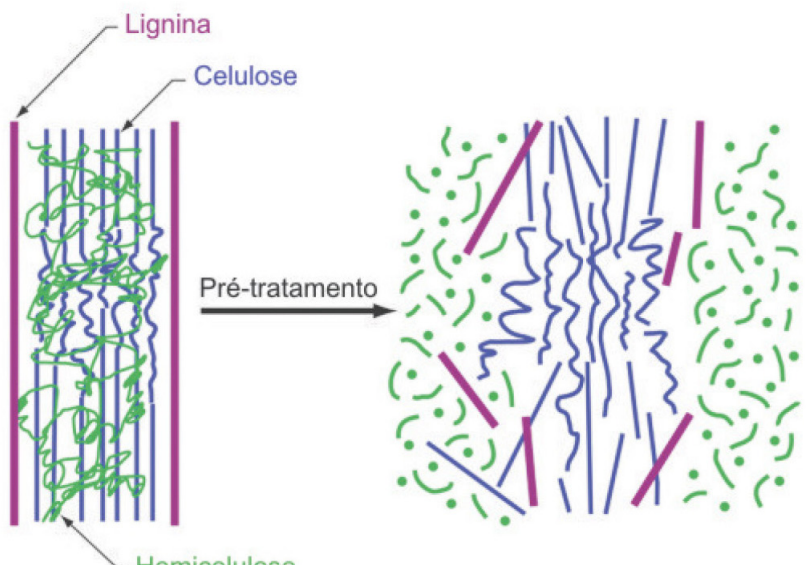

Esquema 4. Alterações estruturais do complexo celulose-hemicelulose-lignina determinadas pelo pré-tratamento. Adaptado da ref. 37 degradar a cadeia celulósica. Como a lignina está quimicamente ligada às hemiceluloses, uma degradação parcial das hemiceluloses ocorre no processo de pré-tratamento químico. ${ }^{2,14,46}$

Várias revisões sobre pré-tratamento foram publicadas nos últimos anos. ${ }^{6,11,51-53} \mathrm{Na}$ Tabela 2 são apresentados de forma simplificada os diferentes tipos de pré-tratamento pesquisados e as respectivas mudanças causadas à biomassa lignocelulósica.

Um pré-tratamento efetivo deve obedecer a uma série de características, tais como, resultar em uma elevada recuperação de todos os carboidratos; resultar em uma elevada digestibilidade da celulose na hidrólise enzimática subsequente; resultar em uma elevada concentração de sólidos, além de uma elevada concentração de açúcares livres na fração líquida; requerer uma baixa demanda energética; evitar a formação de subprodutos; requerer baixo investimento e custo operacional. $6,11,51$

Dentre estas técnicas de pré-tratamento da biomassa lignocelulósica, pode-se destacar a explosão a vapor, AFEX e utilização de ácido diluído como os métodos mais estudados e promissores no processo de obtenção de etanol a partir da biomassa lignocelulósica ${ }^{46}$ (Esquema 5).

O pré-tratamento comumente utilizado para a palha de cana tem sido o pré-tratamento físico, baseado na redução do tamanho das partículas. Este método visa agregar valor a esses materiais por meio de sua classificação mecânica, o que permitirá obter um material de adequada composição físico-química para posterior conversão bioquímica ou termoquímica. ${ }^{30}$

No entanto, a palha de cana-de-açúcar quando submetida ao pré-tratamento com ácido diluído transforma a maior parte da fração hemicelulósica através da hidrólise em monossacarídeos (xilose,

Tabela 2. Efeito de diferentes pré-tratamentos nos matériais lignocelulósicos. Adaptada da ref. 62

\begin{tabular}{|c|c|c|c|c|c|c|}
\hline \multirow{2}{*}{ Pré-tratamento } & & \multicolumn{3}{|c|}{ Características composicionais } & \multirow{2}{*}{ Vantagens } & \multirow{2}{*}{ Desvantagens } \\
\hline & & Celulose & Hemicelulose & Lignina & & \\
\hline Físico & Moinho de bolas & $\begin{array}{c}\text { Intensiva } \\
\text { diminuição do grau } \\
\text { de cristalinidade }\end{array}$ & Não remove & Não remove & $\begin{array}{l}\text { Redução de } \\
\text { cristalinidade }\end{array}$ & Alto consumo de energia \\
\hline \multirow{6}{*}{ Químico } & Ácido diluído & $\begin{array}{c}\text { Pouca } \\
\text { despolimerização }\end{array}$ & $\begin{array}{l}80-100 \% \text { de } \\
\text { remoção }\end{array}$ & $\begin{array}{l}\text { Pouca remoção, mas } \\
\text { ocorre mudança da } \\
\text { estrutura }\end{array}$ & $\begin{array}{l}\text { Condições médias, } \\
\text { altas produção de } \\
\text { xilose }\end{array}$ & $\begin{array}{l}\text { Difícil recuperação } \\
\text { do ácido, corrosivo e } \\
\text { relativamente custoso }\end{array}$ \\
\hline & Hidróxido de sódio & $\begin{array}{l}\text { Inchação } \\
\text { significativa }\end{array}$ & $\begin{array}{l}\text { Considerável } \\
\text { solubilidade }\end{array}$ & $\begin{array}{c}\text { Considerável } \\
\text { solubilização, }>50 \%\end{array}$ & $\begin{array}{l}\text { Remoção efetiva de } \\
\text { ésteres }\end{array}$ & $\begin{array}{c}\text { Reagente caro, recuperação } \\
\text { alcalina }\end{array}$ \\
\hline & ARP & $\begin{array}{l}\text { Menor que } 5 \% \text { de } \\
\text { despolimerização }\end{array}$ & $\begin{array}{c}\sim 50 \% \text { de } \\
\text { solubilidade }\end{array}$ & $\begin{array}{c}\sim 70 \% \text { de } \\
\text { solubilização }\end{array}$ & $\begin{array}{c}\text { Efetiva } \\
\text { deslignificação }\end{array}$ & $\begin{array}{l}\text { Recuperação alcalina, } \\
\text { relativamente caro }\end{array}$ \\
\hline & Hidróxido de cálcio & $\begin{array}{c}\text { Pouca } \\
\text { despolimerização }\end{array}$ & $\begin{array}{l}\text { Significativa } \\
\text { solubilização }\end{array}$ & $\begin{array}{c}\text { Solubilização } \\
\text { parcial }(\sim 40 \%)\end{array}$ & $\begin{array}{l}\text { Efetiva remoção } \\
\text { de lignina e acetil, } \\
\text { baixo custo }\end{array}$ & $\begin{array}{l}\text { Menor efetividade devido a } \\
\text { pouca solubilidade da cal }\end{array}$ \\
\hline & Ozonólise & $\begin{array}{l}\text { Não foi observada } \\
\text { despolimerização }\end{array}$ & $\begin{array}{c}\text { Pequena } \\
\text { solubilização }\end{array}$ & $\begin{array}{c}\text { Solubilização acima } \\
\text { de } 70 \%\end{array}$ & $\begin{array}{c}\text { Efetiva } \\
\text { deslignificação em } \\
\text { condições suaves }\end{array}$ & $\begin{array}{c}\text { Caro, necessidade de mais } \\
\text { ozônio }\end{array}$ \\
\hline & Organosolv & $\begin{array}{l}\text { Considerável } \\
\text { inchação }\end{array}$ & $\begin{array}{l}\text { Significativo, quase } \\
\text { completa }\end{array}$ & $\begin{array}{l}\text { Significativo, pode } \\
\text { ser quase completa }\end{array}$ & $\begin{array}{l}\text { Alta produção } \\
\text { de xilose, efetiva } \\
\text { deslignificação }\end{array}$ & $\begin{array}{l}\text { Recuperação de solvente } \\
\text { cara }\end{array}$ \\
\hline Biológico & Biológico & $\begin{array}{c}20-30 \% \text { de } \\
\text { despolimerização }\end{array}$ & $\begin{array}{l}\text { Acima de } 80 \% \text { de } \\
\text { solubilização }\end{array}$ & $\begin{array}{c}\sim 40 \% \text { de } \\
\text { deslignificação }\end{array}$ & $\begin{array}{c}\text { Baixo requerimento } \\
\text { de energia, efetiva } \\
\text { deslignificação }\end{array}$ & $\begin{array}{l}\text { Perda de celulose, baixa } \\
\text { taxa de hidrólise }\end{array}$ \\
\hline \multirow[b]{2}{*}{ Combinado } & Explosão a vapor & $\begin{array}{c}\text { Pouca } \\
\text { despolimerização }\end{array}$ & $\begin{array}{l}80-100 \% \text { de } \\
\text { remoção }\end{array}$ & $\begin{array}{l}\text { Pouca remoção, mas } \\
\text { ocorre mudança da } \\
\text { estrutura }\end{array}$ & $\begin{array}{l}\text { Energia eficiente, } \\
\text { nenhum custo de } \\
\text { reciclagem }\end{array}$ & $\begin{array}{l}\text { Degradação da xilana como } \\
\text { produto inibitório }\end{array}$ \\
\hline & AFEX & $\begin{array}{l}\text { Diminuição do grau } \\
\text { de cristalinidade }\end{array}$ & $\begin{array}{l}\text { Acima de } 60 \% \text { de } \\
\text { solubilidade }\end{array}$ & $\begin{array}{c}10-20 \% \text { de } \\
\text { solubilização }\end{array}$ & $\begin{array}{l}\text { Menor perda } \\
\text { de xilanas, não } \\
\text { formação de } \\
\text { inibidores }\end{array}$ & $\begin{array}{l}\text { Recuperação de amônia, } \\
\text { não é efetivo para alta } \\
\text { concentracão de lignina }\end{array}$ \\
\hline
\end{tabular}




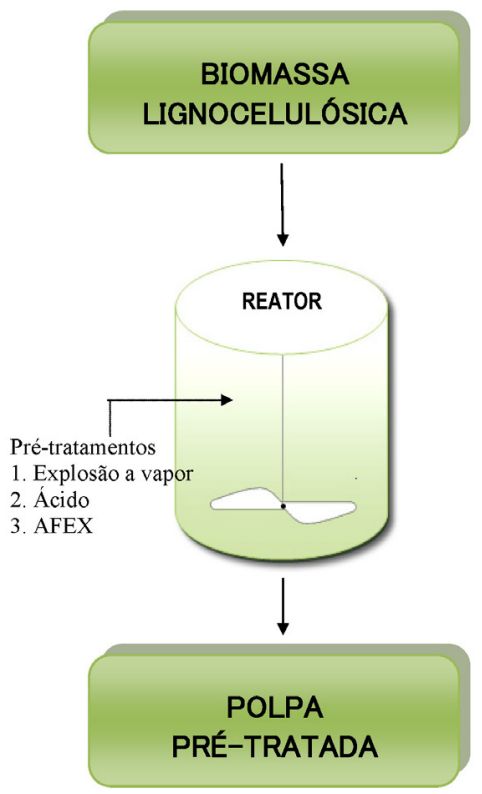

Esquema 5. Representação esquemática dos pré-tratamentos: (1) explosão a vapor: vapor saturado $\left(160-240^{\circ} \mathrm{C}\right)$ no tempo $(2-30 \mathrm{~min})$; (2) ácido: solução com ácido (sulfúrico, clorídrico, fosfórico ou nítrico), temperatura (140-200 ${ }^{\circ} \mathrm{C}$ ), tempo (10-60 min) e pressão (9-17 bar); (3) AFEX: amônia líquida, temperatura $\left(100-180^{\circ} \mathrm{C}\right)$, tempo (10-60 $\left.\mathrm{min}\right)$ e pressão (9-17 bar)

arabinose, e outros). Este método tem se destacado por ser eficiente, rápido e simples. ${ }^{20,54}$ Como consequência, a palha pré-tratada apresenta um escurecimento em relação ao material in natura. ${ }^{34} \mathrm{O}$ escurecimento da palha pode estar associado à formação de produtos da degradação de carboidratos, devido à catálise ácida. Neste pré-tratamento, ocorre a quebra das ligações glicosídicas alterando a estrutura da parede celular vegetal, favorecendo a acessibilidade das enzimas para a hidrólise subsequente da celulose. ${ }^{55}$

O pré-tratamento ácido hidrolisa a hemicelulose e solubiliza parte da celulose,${ }^{34}$ provavelmente grande parte da celulose amorfa ou de baixa cristalinidade, e torna a fração celulósica remanescente mais susceptível à ação das celulases. ${ }^{56}$

Silva ${ }^{31}$ observou que o pré-tratamento com ácido diluído e a deslignificação aumentam o tamanho dos poros e reduzem a cristalinidade da celulose, de forma a melhorar sua conversão enzimática. Tal fato é justificado pela redução da recalcitrância da biomassa lignocelulósica, consequentemente, pela remoção da hemicelulose e lignina, as quais são estruturas amorfas com grau de polimerização bastante inferior ao da celulose. ${ }^{15,16}$

Comparado ao pré-tratamento com ácido diluído, o processo hidrotérmico oferece várias vantagens: não requer o uso de ácidos e, consequentemente, não há necessidade de se trabalhar com reatores altamente resistentes à corrosão, reduzindo o custo deste processo. ${ }^{47}$ Petersen et al.${ }^{57}$ estudaram a otimização do pré-tratamento hidrotérmico de palha de trigo para a produção de etanol. Os experimentos mostraram que as melhores condições de pré-tratamento foram de $195{ }^{\circ} \mathrm{C}$ durante 6 a $12 \mathrm{~min}$, obtendo-se uma recuperação de aproximadamente $70 \%$ de hemicelulose, $94 \%$ de celulose, sendo que $89 \%$ desta celulose podem ser convertidas em etanol.

Entretanto, o pré-tratamento com ácido diluído tem a vantagem de não apenas solubilizar a hemicelulose, mas também de convertê-la em açúcares fermentescíveis, o que elimina ou reduz a necessidade de se utilizar hemicelulases nos complexos enzimáticos durante a etapa de hidrólise enzimática. ${ }^{58}$

Vários métodos têm sido propostos na literatura para obtenção de etanol celulósico para diferentes biomassas. No entanto, para a palha de cana-de-açúcar são escassas as informações necessárias referentes ao seu potencial aproveitamento para produção de etanol, sendo necessários mais estudos com objetivo de conseguir um maior e melhor entendimento dos fenômenos envolvidos na sua conversão bioquímica e, portanto, alcançar um maior rendimento e eficiência de processo, além de menores impactos ambientais.

\section{CONSIDERAÇÕES FINAIS}

Atualmente, várias metodologias de pré-tratamento estão sendo extensivamente estudadas. No entanto, nenhuma dessas pode ser declarada "vencedora" já que cada uma tem suas vantagens e desvantagens intrínsecas. ${ }^{6,40}$

Diversos centros de pesquisas estão buscando novas tecnologias no intuito de viabilizar economicamente a técnica para produção de etanol celulósico. No Canadá, o centro de pesquisa Iogen Corporation está otimizando o pré-tratamento de explosão a vapor para melhorar a digestibilidade enzimática da palha para produção de etanol celulósico com expectativa de produção de $340 \mathrm{~L}$ por tonelada de fibra. ${ }^{59}$

O Departamento de Energia dos EUA também tem apoiado diversos programas de biocombustíveis através de laboratórios, tais como National Renewable Energy Laboratory (NREL), Great Lakes Bioenergy Research Center (GLBRC) e o Oak Ridge National Laboratory (ORNL).

No Brasil, diversos grupos vêm estudando e trabalhando efetivamente na produção de biocombustíveis, que vai desde o melhoramento genético, modelos de produção, rotas tecnológicas, biotecnologia e todos os seus desdobramentos. Em 2003, os laboratórios brasileiros completaram a identificação de 40.000 genes da cana-de-açúcar, cujas informações serão empregadas em programas experimentais de melhoria genética.

Recentemente no Brasil, foi criado o Laboratório Nacional de Ciência e Tecnologia do Bioetanol (CTBE), que investe em pesquisa básica e inovação tecnológica, para viabilização de fontes renováveis de energia que aliem alta produtividade ao aproveitamento máximo da biomassa lignocelulósica com sustentabilidade.

Por fim, a demanda futura por etanol com alta eficiência e sustentabilidade projeta a necessidade de aumentar significativamente sua produção nos próximos anos. Esse aumento poderá ser alcançado pela introdução de novas cultivares de cana-de-açúcar e pelo aproveitamento integral da cana, a palha e o bagaço, para produção de etanol e outros combustíveis renováveis, ou mesmo por meio da biorrefinaria. $\mathrm{O}$ aproveitamento da palha de cana-de-açúcar pode contribuir significativamente para este aumento.

\section{REFERÊNCIAS}

1. Kheshgi, H. S.; Prince, R. C.; Marland, G.; Annu. Rev. Energy Environ. 2000, 25, 1999.

2. Himmel, M. E.; Ding, S. Y.; Johnson, D. K.; Adney, W. S.; Nimlos, M. R.; Brady, J. W.; Science 2007, 315, 804.

3. Lal, R.; Science 2004, 304, 1623.

4. Canilha, L.; Milagres, A. M. F.; Silva, S. S.; Silva, J. B. A.; Felipe, M. G. A.; Rocha, G. J. M.; Carvalho, W.; Rev. Anal. 2010, 44, 48.

5. Felipe, M. G. A. Em Bioetanol de Cana-de-Açúcar: P\&D para Produtividade Sustentabilidade; Cortez, L. A. B., ed.; Edgard Blücher Ltda: São Paulo, 2010, cap. 3 parte 4.

6. Zheng, Y. I.; Pan, Z.; Zhang, R.; Wang, D.; Appl. Energy 2009, 86, 2459.

7. Galbe, M.; Zacchi, G. Em ref. 5, cap. 12 parte 4.

8. Zhang, Y. H. P.; Lynd, L. R.; Biotechnol. Bioeng. 2004, 88, 797.

9. Reddy, N.; Yang, Y.; Trends Biotechnol. 2005, 23, 22.

10. Zhang, Y. H. P.; J. Ind. Microbiol Biotechnol. 2008, 35, 367.

11. Galbe, M.; Zacchi, G.; Adv Biochem Engine/Biotechnol. 2007, 108, 41. 
12. Das, H.; Singh, S. K.; Crit. Rev. Food Sci. Nutr. 2004, 44, 77.

13. Ripoli, T. C. C.; Sci. Agric. 2000, 57, 677.

14. Sun, Y.; Cheng, J.; Bioresour. Technol. 2002, 83, 1.

15. Zhao, X. B.; Wang, L.; Liu, D. H.; J. Chem. Technol. Biotechnol. 2008, 83, 950.

16. Fengel, D.; Wegener, G.; Wood Chemistry, Ultrastruture, Reactions, Walter de Gruyter: Berlin, 1989.

17. Buckeridge, M. S.; dos Santos, W.; Souza, A. P. Em ref. 5, cap. 7.

18. Atalla, R. H.; Hackney, J. M.; Uhlin, I.; Int. J. Biol. Macromol. 1993, $15,109$.

19. Ding, S. Y.; Himmel, M. E.; J. Agric. Food Chem. 2006, 54, 597.

20. Ramos, L. P.; Quim. Nova 2003, 26, 863.

21. Lu, Y.; Yang, B.; Gregg, D.; Saddler, J. N.; Mansfield, S. D.; Appl. Biochem. Biotechnol. 2002, 98, 641.

22. Magalhães, P. S. G.; Braunabeck, O. A. Em ref. 5, cap. 13.

23. Gomez, E. O.; Souza, R. T. G.; Rocha, G. J. M.; Almeida, E.; Cortez, L. A. B. Em ref. 5, cap. 9.

24. Ripoli, T. C. C.; Ripoli, M. L. C. Em Cana-de-Açúcar: Bioenergia, Açúcar e Álcool - Tecnologias e Perspectivas; Santos, F.; Borém, A.; Caldas, C.; eds.; Ed. da UFV: Viçosa, 2010, cap. 10.

25. http://www.ctcanavieira.com.br, acessada em Outubro 2010.

26. Matsuoka, S.; Bressiane, J.; Maccheroni W.; Fouto, I. Em ref. 24, cap. 18.

27. Rabelo, S. C.; Costa, A. C.; Rossel, C. E. V. Em ref. 24, cap. 17.

28. Bonomi, A. Em ref. 5, cap. 11.

29. Abramo, F.; Matsuoka, S.; Álcool e Açúcar 1993, 67, 23.

30. Olivares, E. G.; Cortez, L. A. B.; Roca, G. A. A.; Brossard, L. E.; Resumos do $7^{\circ}$ Congresso Internacional Sobre Geração Distribuída e Energia no Meio Rural - Semiárido, Energia e Desenvolvimento Sustentável-Agrener, Anais, Brasil, 2008.

31. Silva, V. F. N.; Dissertação de Mestrado, Universidade de São Paulo, Brasil, 2009.

32. Aguilar, A.; Penã, U.; Friedman, P.; Brito, B.; Rev. Cuba Azúcar EneroMarzo, 1989, 40.

33. Paes, L. A. D.; Seminário Alternativas Energéticas a Partir da Canade-Açúcar, Centro de Tecnologia Canavieira, CTC, Piracicaba, Brasil, 2005.

34. Paula, M. P.; Dissertação de Mestrado, Universidade de São Paulo, Brasil, 2009.

35. http://www.genomics.energy.gov, acessada em Outubro 2010.

36. Converse, A. O.; Ware, W.; Workshop on Applications of Biotechnology in Bioenergy Systems, Ottawa, Canadá, 1994.
37. Kondo, T.; J. Polym. Sci.: Part B: Polym. Physics 1997, 35, 717.

38. Regiani, A. M.; Marson, G.; El Seoud, O. A.; Frollini, E. Em Natural Polymers and Composites; Mattoso, L. H. C.; Frollini, E.; Leão, A., eds.; São Carlos: Unesp/Embrapa/USP: São Carlos, 1998, p. 239-253.

39. Farinas, C. S.; Neto, L. M.; Giordano, R. C. Em ref. 5, cap. 12.

40. Sannigrahi, P.; Miller, S.; Ragauskas, A. J.; Carbohydr. Res. 2010, 345, 965.

41. Chang, V. S.; Nagwani, M.; Holtzapple, M. T.; Appl. Biochem. Biotechnol. 1998, 74, 135.

42. Zhang, Y. H. P.; Lynd, L. R.; Biotechnol. Bioeng. 2006, 94, 888.

43. Hong, J. Y.; Zhang, Y. H. P.; Langmuir 2007, 23, 12535.

44. Zhang, Y. H. P.; Ding, S. Y.; Mielenz, J. R.; Elander, R.; Laser, M.; Himmel, M.; Mcmillan, J. D.; Lynd, L. R.; Biotechnol. Bioeng. 2007, 97 , 214.

45. Jorgensen, H.; Kristensen, J. B.; Felby, C.; Biofuels Bioprod. Bioref. 2007, $1,119$.

46. Mosier, N.; Wyman, C.; Dale, E, B.; Elander, R.; Lee, Y. Y.; Holtzapple, M.; Bioresour. Technol. 2005, 96, 673.

47. Wyman, C. E.; Dale, B. E.; Elander, R. T.; Holtzapple, M.; Ladisch, M. R.; Lee, Y. Y.; Bioresour. Technol. 2005, 96, 1959.

48. Wooley, R.; Ruth, M.; Glassner, D.; Sheehan, J.; Biotechnol. Prog. 1999, 15, 794.

49. Chang, V. S.; Holtzapple, M. T.; Appl. Biochem. Biotechnol. 2000, 5, 37.

50. Kim, S.; Holtzapple, M. T.; Bioresour. Technol. 2006, 97, 583.

51. Taherzadeh, M. J.; Karimi, K.; Int. J. Mol. Sci. 2008, 9, 1621.

52. Hu, G.; Heitmann, A.; Rojas, O. J.; Bioresour. Technol. 2008, 270, 294.

53. Hendriks, A. T. W. M.; Zeeman, G.; Bioresour. Technol. 2009, 100, 10.

54. Parajó, J. C.; Domínguez, H.; Domínguez, J. M.; Bioresour. Technol. 1998, 66, 25

55. Curreli, N.; Agelli, M.; Pisu, B.; Rescigno, A.; Sanjust, E.; Rinaldi, A.; Proc. Biochem. 2002, 37, 937.

56. Hodge, D. B.; Karim, M. N.; Schell, D. J.; Mcmillan, J. D.; Bioresour. Technol. 2008, 99, 8940.

57. Petersen, M. O.; Larsen, J.; Thomsen, M. H.; Biomass Bioenerg. 2009, $33,834$.

58. Saha, B. C.; Iten, L. B.; Cotta, M. A.; Wu, Y. V.; Proc. Biochem. 2005, 40, 3693.

59. http://www.iogen.ca/cellulosic_ethanol/process, acessada em Outubro 2010 